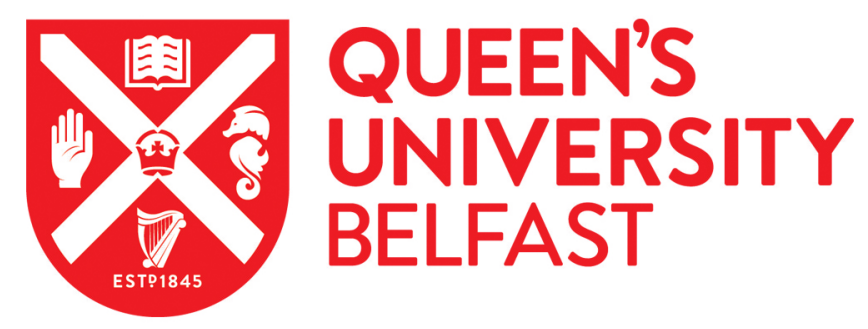

\title{
Vulnerability and robustness of SME supply chains: An empirical study of risk and disturbance management of fresh food processors in a developing market
}

Vlajic, J. V. (2015). Vulnerability and robustness of SME supply chains: An empirical study of risk and disturbance management of fresh food processors in a developing market. In R. Bhamra (Ed.), Organisational Resilience: Concepts, Integration, and Practice (pp. 85-102). CRC press, Taylor and Francis.

https://www.crcpress.com/Organisational-Resilience-Concepts-Integration-and-

Practice/Bhamra/9781482233568

Published in:

Organisational Resilience: Concepts, Integration, and Practice

\section{Document Version:}

Peer reviewed version

\section{Queen's University Belfast - Research Portal:}

Link to publication record in Queen's University Belfast Research Portal

\section{Publisher rights}

Copyright 2016 by Taylor \& Francis Group, LLC

This is an Accepted Manuscript of a book chapter published by Routledge in Organisational Resilience: Concepts, Integration, and Practice on 5 October 2015, available online: https://www.crcpress.com/Organisational-Resilience-Concepts-Integration-and-

Practice/Bhamra/9781482233568

\section{General rights}

Copyright for the publications made accessible via the Queen's University Belfast Research Portal is retained by the author(s) and / or other copyright owners and it is a condition of accessing these publications that users recognise and abide by the legal requirements associated with these rights.

\section{Take down policy}

The Research Portal is Queen's institutional repository that provides access to Queen's research output. Every effort has been made to ensure that content in the Research Portal does not infringe any person's rights, or applicable UK laws. If you discover content in the Research Portal that you believe breaches copyright or violates any law, please contact openaccess@qub.ac.uk. 


\title{
Vulnerability and robustness of SME supply chains: An empirical study of risk and disturbance management of fresh food processors in a developing market
}

\author{
Jelena V. Vlajic \\ Queen’s University Belfast, Queen’s Management School \\ E-mail:J.Vlajic@qub.ac.uk
}

\begin{abstract}
The aim of this paper is to analyse vulnerability and robustness of small and medium size enterprises (SMEs) supply chains and to consider contextual factors that might influence the success of their disturbance management: Risky product and business environment. By using an exploratory case study it is shown how these contextual factors attribute vulnerability sources, contribute to the robustness of a company’s performance and supply chain vulnerability, as well as how a company seeks to manage internal and external vulnerability sources. The exploratory case is based on a fresh food supply chain of a manufacturing SME operating in a developing market.

Case findings suggest that fresh food supply chains of a manufacturing SME in developing markets are prone to disruptions of their logistics and production processes due to 'riskiness' of fresh food products, the 'riskiness' of developing markets, as well as 'riskiness' of SMEs themselves. However, this does not necessarily indicate the vulnerability of an SME and its entire supply chain. Findings indicate that SMEs can be very successful in disturbance management by selective use of redesign strategies that aim to prevent or reduce the impact of disturbances. More precise, it is likely that an SME can achieve robust performance by employing preventive redesign strategies in managing
\end{abstract}


disturbances that result from internal, company related vulnerability sources, while impact reduction strategies are likely to contribute to robust performance of an SME if used to manage disturbances that result from internal, supply chain related vulnerability sources, as well as external vulnerability sources.

Keywords: Disturbances, Small and Medium Enterprises, risky food products, vulnerability sources, redesign strategies

\section{Introduction}

The supply chain literature offers different insights into the vulnerability of SME supply chains. Some researchers found that SMEs' supply chains are less vulnerable in comparison with supply chains of large organizations (Wagner and Neshat, 2012), while others found that SMEs’ supply chains are more vulnerable in comparison with supply chains of large organizations (Thun et al., 2011; Arend and Wisner, 2005). Differences in these findings can be explained by the existence of contextual factors that influence results. SMEs are often presented as vulnerable due to limited organizational, financial and human resources (Vaaland and Heide, 2007). Considering that a supply chain is as strong as its weakest link (Kleindorfer and Saad, 2005; Slone et al., 2007), these findings do not actually indicate how vulnerable SME's supply chains are. Moreover, the literature does not offer explanations of which contextual factors can influence the level of vulnerability of SMEs' supply chains, nor the capabilities of SMEs to decrease their vulnerability and maintain robust performance.

The objective of this study is to shed light on these issues by investigating the level of the SME's vulnerability and by analysing to what extent characteristics of 'risky' products and risks related to the business environment contribute to SME's supply chain capability to manage disturbances. Moreover, additional insights are provided for the type of redesign strategies the SME might select to maintain robust performance and to decrease vulnerability. This research contributes to the supply chain risk 
management literature with insights on the SME's supply chain vulnerability and its capability to manage disturbance when exposed to the influence of contextual factors that increase risks to SMEs' supply chain.

This paper is structured as follows. Section 2 is devoted to an application of a theoretical framework for achieving robust supply chains to SME's supply chain. In this section, contextual factors that might influence the success of SME to manage disturbance such as the riskiness of the product, and riskiness of the business environment are also considered. The employed methodology and the use of an exploratory case study to investigate how these contextual factors contribute to robustness of the company's performance and supply chain vulnerability while the company manages internal and external vulnerability sources are described in Section 3. Sections 4 and 5 are focused on a brief case description and the main findings related to the company's vulnerability levels in relation to susceptibility to various types of disturbance and the capability of the company to manage these disturbances and their vulnerability sources.

\section{A Theoretical Framework}

In the supply chain management literature, robustness is considered as the ability of a supply chain to continue to function well even when faced with disturbances in its processes (Dong, 2006; Tang, 2006; Waters, 2007; Stonebraker et al., 2009; Weiland and Wallenburg, 2012; Vlajic et al. 2013). 


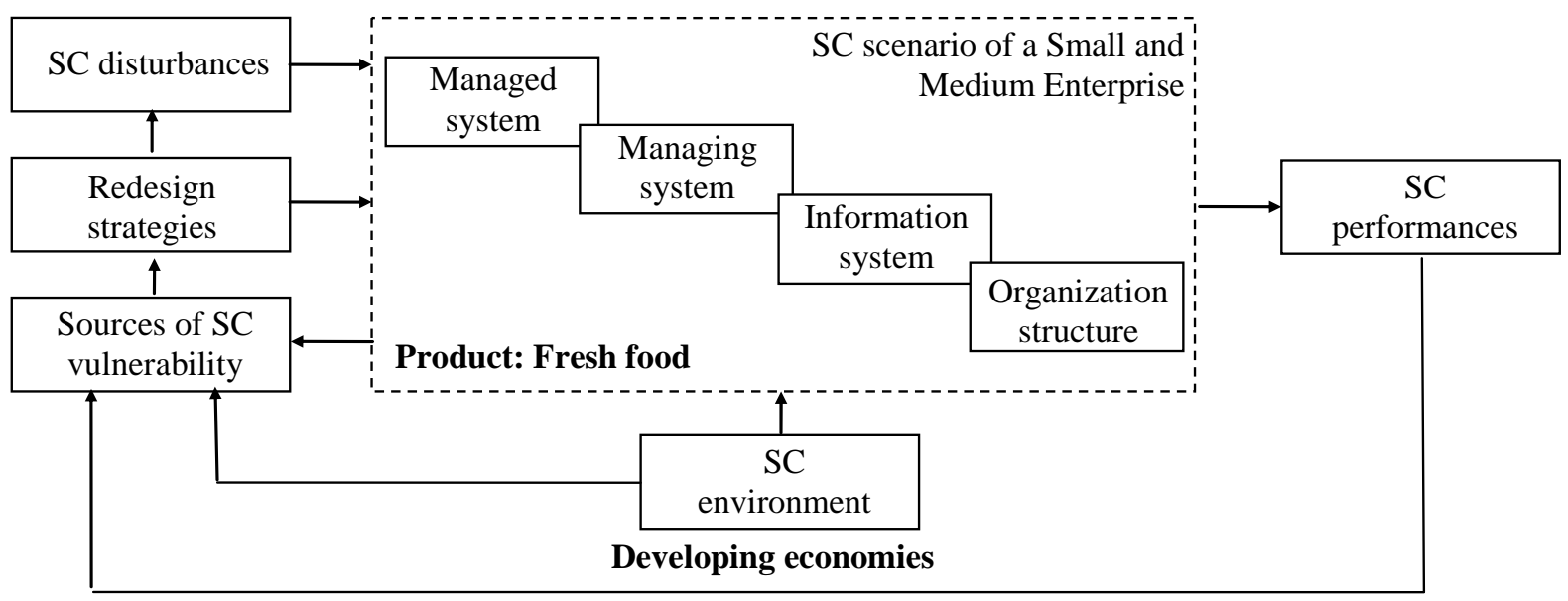

Legend: SC - supply chain $\quad$ Bold letters - contextual factors

Figure 1: Framework for achieving robust supply chains (adapted from Vlajic et al., 2012)

Generally, to achieve robustness supply chains have to manage disturbances successfully. Vlajic et al., (2012) developed a framework for robust supply chains that considers the main building blocks for successful disturbance management and relations between them. The first building block is a supply chain scenario, which represents an internally consistent view of a possible instance of the logistics supply chain concept (van der Vorst, 2000). This concept consists of a managed system (physical design of a network, fixed and mobile resources), a managing system (planning, control and coordination of logistic processes), an information system (information and decision support systems) and an organizational structure (tasks, responsibilities, and authorities of departments and employees). As a supply chain normally consists of multiple participants, from multinational companies to SMEs, connected together by flows of materials, information and finance, analysis of the supply chain scenario is usually centred on the focal company (c.f. Lambert and Cooper, 2000).

Robustness of the supply chain scenario is reflected in its performance. Any deviation of a defined performance range indicates the presence of disturbances in the supply chain process and increased 
supply chain vulnerability. Disturbances are considered on the process level, and detect them as any deviation from quantity, quality and time related specifications.

To manage disturbances successfully, two types of redesign strategies can be used. In this context, redesign strategies are defined as strategic and tactical plans, leading to operational actions that aim to reduce the vulnerability of the supply chain by making changes in core elements of the supply chain scenario (Vlajic et al., 2012). The first type of redesign strategies aims to prevent disturbances by avoiding or reducing the probability of exposure to vulnerability sources (Wagner and Bode, 2009). Vulnerability sources may cause disturbances and, in the literature, are categorized as external or internal (Asbjørnslett and Rausand 1999). External vulnerability sources consider market, societal, infrastructural, financial, legal and environmental factors in a supply chain's business environment. These are considered as uncontrollable from the company's standpoint. Internal vulnerability sources are concerned with the supply chain and the company's perspective of the supply chain scenario (Vlajic, 2012) and are considered as controllable to the some extent (Simchi-Levi et al., 2008). The importance of vulnerability sources can be assessed by investigating how often they cause disturbances, the extent to which performances are outside specifications when disturbance occurs, and how easy it is to detect the disturbance and its cause. The second type of redesign strategies aims to mitigate the impact of disturbances by modifying elements of the SC scenario, so that impact of disturbances in amortized, e.g. by keeping buffer stocks or increasing process flexibility (Wagner and Bode, 2009).

The selection of a particular redesign strategy depends on the characteristics of disturbances and its vulnerability sources (Vlajic et al., 2013). While the majority of papers in the supply chain risk management literature focuses on identification and analysis of risks and disturbances, as well as identification of appropriate or optimal redesign strategies that can be used when disturbances occur, there is little research devoted to opportunities and challenges of small and medium enterprises (SMEs) for successful disturbance management. 
By comparison with large companies SMEs are perceived as slightly more vulnerable (Thun et al., 2011) for the following reasons: A typically smaller assortment, fewer customers and lower volume, higher capital and transaction costs, a reactive nature in the company's strategies, and the presence of limited resources (Arend and Wisner, 2005). Moreover, SMEs usually have more difficulties managing business processes in the global environment and in overcoming entry and trading barriers (Ritchie and Brindley, 2000). Additionally, they usually operate under conditions of a weaker cash flow and lower equity reserves (Thun et al., 2011). However, SMEs are often characterized by informal exchanges of information between employees (Roebuck et al., 1995), knowledge of local markets, knowledge-based advantages (Arend and Wisner, 2005) and flexible organizational structure (Vaaland and Heide, 2007). Thus, some findings indicate that lesser complexity of business situations of SMEs makes them less vulnerable than large companies, (cf. Wagner and Neshat, 2012).

The literature implies that SMEs have difficulties in managing disturbances, but also that they might have advantages in using certain sets of redesign strategies for managing disturbances caused by internal and external vulnerability sources. Considering specificities of the SME’s supply chains, it would be important to obtain additional insights into level of SME's supply chains, i.e., susceptibility to disturbances in its processes.

Moreover, an SME's vulnerability and robustness of its performances might depend on specificities of vulnerability sources and the capability of companies to implement adequate redesign strategies. These specificities are captured by relevant contextual factors. For this study, characteristics of a product and supply chain business environment are selected as relevant contextual factors. If characterised as risky, both product and supply chain business environment characteristics might contribute to supply chain vulnerability. Considering product characteristics, fresh food products for example have a huge 'risk’ potential (Henson and Reardon, 2005), due to specific product characteristics (e.g. shelf life constraints, sensitivity to temperature changes and environmental conditions, biological variations, long production throughput times) and influence operations in logistics processes (van der Vorst, 2000). 
While the literature recognizes risk associated with certain types of products, and consequential limitations in the management and organization of logistics processes, it is not known to what extent characteristics of 'risky' products might restrain possibilities of SME for disturbance management and what strategies SME might use to manage these disturbances.

Considering supply chain business environment characteristics, the following factors might contribute to supply chain vulnerability (Asbjørnslett and Rausand, 1999): financial (e.g. currency fluctuations), market (e.g. price fluctuations, new products launches, fierce competition), social (e.g. civil disturbance), environmental (e.g. natural disasters), infrastructural (e.g. lack of modern road, rail and port infrastructure) and legal (e.g. lack of regulations or low level of regulatory enforcement). However, even in a risky business environment, companies might achieve robustness of their performances by developing reliable relationship with their supply chain partners (c.f. Fynes et al., 2004). Thus, it would be interesting to investigate to what extent characteristics of 'risky' environment might restrain possibilities of SME for disturbance management and what strategies SME might use to manage these disturbances.

\section{Methodology}

Existing theories in the supply chain management literature fail to fully explain the level of exposure of supply chains to vulnerability sources related to the specificities of the products, type of companies involved in the chain and the type of business environment, as well as the mechanisms that can be used to manage consequential disturbances. Thus, an exploratory study is needed to develop pertinent propositions for further inquiry (Yin, 2014). The SME is used as the unit of analysis.

In line with specific characteristics of supply chains that lead to increased vulnerability levels, the following criteria for case selection are used: 
1) The SME in the supply chain: A medium size dairy processor is selected for the exploratory case. The company's core business is the production of a small, traditional assortment of dairy products. The company has a regional supply network and it delivers dairy products to customers in the region. During the selection process, it was identified that the company experiences multiple disturbances during the year.

2) Risky products: Perishable food products are considered as high risks in the literature. These kinds of products affect design and realization of logistics processes - e.g. they limit inventory levels, require frequent testing of product quality and monitoring of production and logistics activities, and, if not managed properly, could create significant costs due to waste of products.

3) Risky market: The chosen SME serves a market in a transition country in the Western Balkans and has a total of around 200 competitors. Transition countries are considered as developing markets, and often as risky business environments for investments (OECD, 2012), as well as having particular infrastructural and legal vulnerability sources. For example, logistics performance indicators (Arvis et al., 2012) highlight challenges with regard to efficiency of customs and clearance processes, quality of trade and transport related infrastructure, ease of arranging competitively priced shipments, competence and quality of logistics services.

Data collection was conducted in 2011. To comply with requirements for data triangulation, data collection is performed by using semi-structured interviews, a field visit, and an inspection of the company's public documents. Interviews were conducted with the company director, the financial director and the quality control technician. Each interview lasted between one and one and a half hours and they were conducted in the factory. The field visit looked at the milk processing operation, the quality of laboratory food safety testing and the factory's distribution storage. The public documents used were the company's newsletters, reports from quality control agencies, and reports from the National Chamber of Commerce relating to the company’s performance. 
The purpose of data collection was to collect data about disturbances that occur in the company, the types of vulnerability sources and how they impact on the company's performance and the type of redesign strategies the company uses to manage such disturbances. Data collection was based on the case study protocol and consisted of semi-structured questions grouped in the following blocks: General data about the company; data about disturbances and their impact on company performance; data about vulnerability sources; and data about redesign strategies used to manage disturbances. In addition to the narrative that developed from the questions, interviewees are asked to estimate the severity of disturbances and the impact of various vulnerability sources on the company's performance. Estimation was based on principles of Process Failure Modes and Effects Analysis (PFMEA), i.e., each identified disturbance and corresponding vulnerability sources was rated from 1 to 7 by each interviewee (e.g. frequency scale: 1 - never, 2 - very rare ... 6 - very frequently and 7 - always) with regard to the frequency of occurrence, impact on performances and ease of detection.

Because the framework and case study protocol are based on selected variables, it was convenient to transform the gathered data to an Effect Matrix, which focused on dependent variables (Miles and Huberman, 1994). Here, the independent variable is a vulnerability source, the dependent variable is disturbance and the intervening variable is redesign strategy. The Effect Matrix enables the analysis and summation of numerical values which indicated what kind and how many vulnerability sources are present in the case study, as well as which and how many vulnerability sources can trigger one disturbance and which and how many different redesign strategies can be used in each instance. Moreover, the estimation of vulnerability levels and a ranking of disturbances are based on the use of Disturbance Priority Number (DPN) values. Due to the emphasis on disturbances, the term Disturbance Priority Number is used rather than Risk Priority Number. According to the PFMEA, a DPN can be estimated as the product of the frequency, the impact and the detectability of a particular disturbance (Scipioni et al, 2002). A DPN value is used as a measure to rank disturbances and their causes, as well as to estimate the vulnerability level of the company. As each of the three dimensions is evaluated on a 
(integer) scale of 1 to 7 the DPN takes values of at least 1 and at most $7^{3}=343$. The higher the DPN value, the higher priority of disturbance or VS is. Vulnerability levels can be estimated in various ways. In this paper, vulnerability levels are defined in relation to qualitative assessment of dimensions, i.e. negligible: [1 - 8], low: (8 - 27], low-medium: (27 - 64], medium: (64-125], medium-high (125-216] and high (216-343].

\section{Case description}

Considering the number of employees and annual turnover, the milk processing company is classified as a medium size company. In the following sections, a case description is provided by using elements of the supply chain scenario.

Managed system: The company consists of the factory with specialized equipment for milk processing, cold storage for raw milk and milk products, distribution fleet, laboratory and administrative offices. The company also owns several small retail outlets in the region. The company produces three groups of products: fresh milk, plain yogurt, and cheese. Fresh milk is the most perishable product (5 days of shelf life), while cheese has a longer shelf life (soft cheese up to five weeks and hard cheese up to several months). All products are preserved in protective packaging made of carton and plastic materials.

The company delivers its products to 2000 customers consisting of a small number of large retailers and a large number of small, privately owned retail outlets and food service companies. The company sources raw milk from around 800 suppliers.

Managing system: The company processes 40,000 litres of raw milk per day on average. The production plan and product assortment is based on consideration of the demand of large customers (annual contracts) and a forecast of the demand of small customers. Due to oscillations in sourcing of raw milk and the inability to store raw milk, the company sources larger quantities than is needed for daily production. After the fulfilment of planned production remaining raw milk is used for production 
of cheeses (less perishable products). Part of the managing system is related to supplier management, i.e., the company makes planned visits to their suppliers to monitor their work (number of animals, their health, breading plans, etc.). The company is also engaged in customer management through promotional activities, such as participation in national competitions focused on product quality.

Information system: The company uses spreadsheets in combination with databases and customized accounting software to support its business operations. These databases consist of modules that store information about customers and their orders, suppliers and their capacities, as well as production capacities and schedules. Information flows are twofold: formal (by e-mails, documentation) and informal (exchange of information in personal conversations).

Organizational structure: The company consists of a few senior staff whose duties are to plan and organize sourcing, production and sales, keep contact with suppliers and customers, perform financial and accounting activities as well as plan and organize distribution. Staff duties and responsibilities are not strictly divided: Alongside the administrative staff the company employs a few workers in production, a full-time certified quality control laboratory manager and a part-time lab-technician.

\section{$5 \quad$ Findings and discussion}

In this section key findings are reported followed by an analytical discussion. First, findings related to the vulnerability level of milk processor's (SME's) supply chain are presented and subsequently more details and analysis of the observed disturbances, their sources and capabilities of milk processor to manage them are discussed.

Results of the PFMEA method applied to the case show that the highest vulnerability level experienced by the milk processor is medium-high (DPN = 144, Figure 2). Though impact is high and detectability of this disturbance is difficult due to the delays in reporting by the customer, this disturbance happens occasionally indicating that milk processor is exposed to this vulnerability source occasionally or that milk processor has mechanisms to manage this disturbance, which requires further 
analysis and discussion. To investigate this, more detailed analysis is presented starting with the consideration of disturbances caused by internal, company related vulnerability sources.

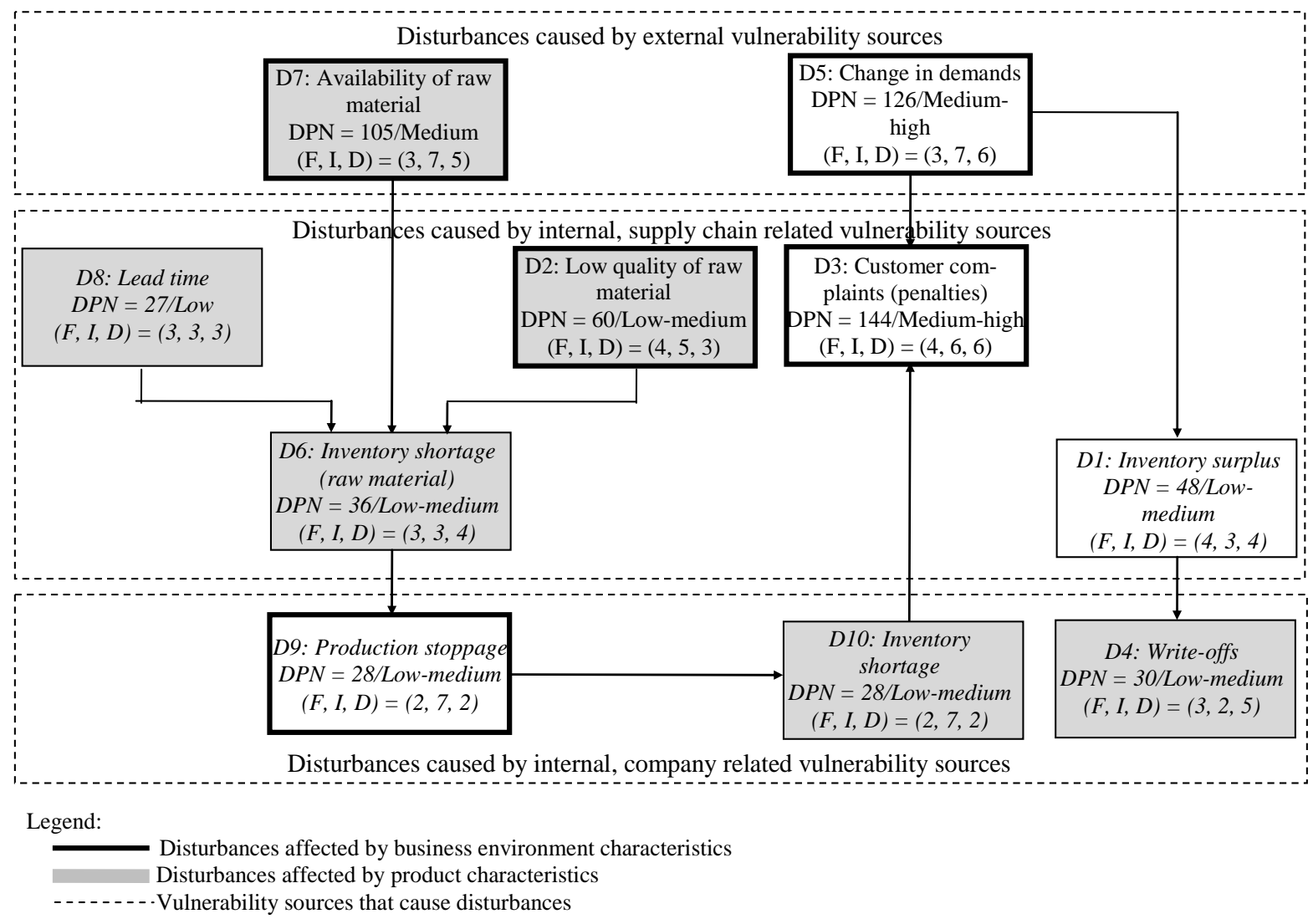

Figure 2. Relation between disturbances (DPN - Disturbance Priority Numbers are estimated independently for each disturbance)

Though Wagner and Neshat (2012) found that SMEs are less vulnerable than large companies, their findings indicate that SMEs are vulnerable. Moreover, they found that companies experience increased vulnerability when producing large series. The milk processor is characterized by production of large volumes and relatively narrow variety, which corresponds to mass production or production of large batches (Slack et al., 2013). 
In combination with their input and output of perishable, "risky" food products (Henson and Reardon, 2005), the milk processor becomes susceptible to disturbances that result from internal, company related vulnerability sources (grey fields in Figure 2). For example, many milk products are temperature sensitive and have a short expiration date. Thus, preservation of right quality of milk products requires specialised, often complex production, storage and transport equipment. Any failure in specialised production equipment can cause large disruptions, not only in quantity produced, but it can also have a detrimental effect on the quality of products and on-time deliveries. Moreover, the cost of investment in specialised equipment, especially in the volatile financial markets experienced in many developing countries might increase the vulnerability of the company. Additionally, the company often has to manage write-offs due to occasional inventory surplus or returned products. Thus, the following proposition can be stated:

P1. If riskiness of the products characterise internal, company related vulnerability sources, then the manufacturing SME’s susceptibility to disturbances is likely increased.

Analysis of DPNs for internal, company related vulnerability sources indicates that the milk processor has a low-medium vulnerability level, i.e., it does not suffer from serious disturbances. Further investigation indicated that the managerial team took a proactive approach to disturbance management even from the design stage, i.e., from thorough preparation and planning of the facility design, via careful budget planning, to planning responses in the case of equipment failure, inventory shortage of final products or products at the inventory that are close to the best-before date. Moreover, as the milk processor uses specialised, foreign manufactured equipment, equipment failure might be a rather serious issue due to uncertain availability of spare parts and knowledge for maintenance of this equipment (Huiskonen, 2001), especially in the context of a developing market (Taylor, 1994). Aiming to reduce frequency of disturbances, the milk processor implemented a set of preventive strategies such as choice 
of reliable production equipment, organization of regular maintenance, analysis of customer demands to drive production planning and reduce piling of inventory of final products and consequential writeoffs. The company would appear to make the right decisions in regard to these issues as according to the financial manager: "in last eleven years, the company had to stop production due to equipment failure only once". Thus, use of all these preventive strategies contributes to the stability of the production system and robustness of its performance. The use of impact reduction redesign strategies is somewhat limited due to product and business environment characteristics. For example, due to the perishable nature of many milk products the milk processor cannot keep large safety stocks of final products and raw materials as insurance against failures of supply or production. Also, to shorten repair times, the producer stocks important spare parts and maintains contacts with certified maintenance teams in the region as well as abroad.

P2. In the presence of product related risks, preventive redesign strategies are likely used by a manufacturing SME to manage disturbances caused by internal, company related vulnerability sources. Riskiness of the business environment might affect the manufacturing SME’s capability to successfully manage disturbances.

The milk processor's supply chain consists of many small farms (suppliers) and two main suppliers for packing material on the one side, and multiple large retail customers and a large number of smaller customers on the other side. Thus, the supply and the demand side of its supply chain are analysed separately.

Looking at the supply side, farms produce small quantities of milk and the quality of the milk might vary due to sickness of animals, variations in quality of animal feed, seasonal variation, etc. Due to high perishability of raw milk, it is not possible to keep a buffer that would shield production. For the same reason, lead time has to be short and as a consequence milk processor has only local suppliers. Low 
quality of raw milk can also be traced to external vulnerability sources in a supply chain where small farmers are not educated sufficiently how to prevent sickness of animals during various seasons, how to plan animal breeding, what feed to use and how to increase farm productivity. For instance, the company director states: "low milk production is a consequence of traditional feed choices and use of traditional cow breeds on the farm". The small size of many farms does not lend itself to high levels of development that might be technically challenging and relatively costly for a small enterprise.

Thus, due to the variability of quantity and quality of suppliers' inputs (van der Vorst, 2000), as well as constraints in the supply base (Giunipero and Eltantawy, 2004) and characteristics of suppliers (Zsidisin, 2003), companies might also become susceptible to disturbances on supply side that result from combination of internal, supply chain related vulnerability sources and riskiness of a product.

Looking at the demand side, large customers (referred to by informants as "powerful retail systems") usually order large quantities of products, have strict specifications about delivery times, prefer to have a large assortment of products in their retail outlets, as well as to organize promotions and present new types of milk products. Customer complaints are considered ('measured') through the return of unsold products and claims due to deliveries being out of specification (e.g. delivered quantity less than ordered, delayed delivery, etc.). This disturbance happens a few times per year, has a high impact on the company's financial performance (in particular, the company has to pay penalties or to take back products) and is difficult to detect early because penalties are often visible only in end of the month reports. More specifically, according to the financial director, "large customers demand use of quantityflexibility contracts”. Quantity-flexibility contracts are risky for a supplier, because the supplier is obliged to provide a full refund for returned (unsold) items as long as the number of returns is not larger than a certain quantity (Simchi-Levi et al., 2008). Typically, the supplier is also obliged to organize and meet the cost of the return of unsold items. Looking at this issue in more detail, field data indicates that 
large customers dictate details of the contracts, i.e., that power imbalance exists (Matopoulos et al., 2007): As company director states: "they [large customers] set the rule for quantity of products in return, as well as for quality parameters. We have to accept that because they cover large percent of market... ”). Large customers also define tolerance specification for delivery and stock-out in their premises, as financial director states: "if they [large customers] have large demand and our products are sold, we have to deliver new batch in very short period of time”. Complaints by large customers that products are out of specification and the resultant product returns give rise to the highest priority disturbance for the milk processor. This is not surprising since powerful retail systems often transfer risk to their suppliers (Peck, 2005), and even impose new systems (e.g. specific types of labelling and packaging) on weaker business partners (Coe and Hess, 2005). This situation is especially present in developing markets, which are characterised by low supply chain transparency (Roth et al., 2008), struggle to comply with food safety standards due to resource limitations (Henson and Humphrey, 2010), incompatibilities of production and marketing systems (Donovan et al., 2001), underdeveloped and/or fragmented retail sector and large number of intermediaries (Lorentz et al., 2013), and food traceability issues (Humphrey, 2007).

Based on analysis of a supply and demand side of the milk processor's supply chain, the following proposition is developed:

P3. When supply and demand related vulnerability sources are characterised by riskiness of the product and riskiness of the business environment, then the manufacturing SME's susceptibility to disturbances is likely increased.

Low availability or low quality of raw milk can cause production stoppages and inventory shortages of final products due to inability of the company to keep a buffer of raw milk. Though the use of impact reduction strategies is again somewhat limited by product characteristics, there is still a number of them 
that can be applied. For example, to reduce impact of disturbances in the case of supplier failure the company orders slightly higher quantities of raw milk than planned, which results in high utilisation of production capacity (c.f. Vlajic et al., 2013). In this way, variation in input does not affect required production output, and the company gets increased flexibility in realisation of the production program. However, this strategy leads to occasional accumulation of the inventory of cheese, a less perishable product which is produced from the surplus of raw milk. In the rare cases of larger disruption in sourcing, the company has in place arrangements to acquire additional quantities of milk from other processors who have a surplus, i.e., emergency transhipment (Simchi-Levi et al., 2008). Moreover, the regular use of their own transport resources and the use of 3PL when needed results in short lead times for emergency deliveries. Looking at the use of preventive strategies, it is noticed that their use is also limited due to restricted resources of the milk processor. "Though our purchasing team has frequent contact with our suppliers, and we belong to the same cooperative, we are not capable of helping them to solve problems at their farms more than giving advices and recommendations”, states the financial director, which implies low ability of the SME to participate in supplier development and develop their network (Singh, et al., 2008). Also, to eliminate possibilities of contamination of high quality milk with low quality milk, the company conducts quality control tests on the farms. This allows the SME to detect this disturbance effectively, although it remains difficult to identify its causes and to prevent it.

The analysis of DPNs for internal, supply chain related vulnerability sources indicates that the milk processor suffers from serious disturbances caused by demand side vulnerability sources. Customer complaints are considered as disturbances related to deviations in quantity or quality of products delivered, and this disturbance causes medium-high vulnerability level and thus has the highest priority. However, the milk processor experiences low-medium vulnerability with respect to inventory surplus of final products and product write-offs because of the redesign strategies used. Collected data indicate that milk processor relies again on impact reduction redesign strategies to manage frequent customer 
complaints with regard to the assortment and changing preferences for milk products by large customers, as well as inventory surplus. The main reason lays in the fact that complex, specialized equipment for milk processing limits the possibilities to increase the variety of final products. Thus, the company is not able to satisfy such demands without costly investment in additional equipment and diversification of customers represents the dominant strategy to manage disturbances (Waters, 2007). Moreover, by keeping a diverse customer base returned products can be sold to customers that have broader tolerance specifications (e.g. processors of pet and domestic animal feeds). Return flows are combined with distribution tasks by using their own fleet, which is considered as good, sustainable logistics practice (Tibben-Lembke and Rogers, 2002; Kleindorfer et al, 2005).

Based on the analysis of redesign strategies used in the supply and the demand side of the milk processor's supply chain, the following proposition can be stated:

P4. In the presence of product related risks, impact reduction redesign strategies are likely used by the manufacturing SME to manage disturbances caused by internal, supply related vulnerability sources, while in the presence of business environment related risks, these strategies are likely used by the manufacturing SME to manage disturbances caused by internal, demand related vulnerability sources.

Further analysis of the vulnerability sources reveals a number of external vulnerability sources that represent root causes of some disturbances discussed above. Field data indicate that the real threat of raw material inventory shortages results from the low availability of raw material on the local market. The challenge here is that it is difficult for milk processor to detect external vulnerability sources, as well as to reduce the frequency and the impact of the disturbances they create. More specifically, the threat is compounded by the poor ability of the control and planning system of the company to identify and manage this disturbance to their supply market. Though low availability of raw material on the local market occurs once every few years, it has huge impact because it affects all companies in the sector. Sector analysis in this developing market revealed that the supply base of the local market is shrinking 
as small farmers are leaving the business. The main reason for this lies in low milk prices on the national market, as well as delays in cash flows. Moreover, suppliers also speculate who to select as a favorable customer and when to leave milk production in favour of other farm production such as cattle rearing. Thus, climate changes that affect feed quality, variability and seasonal peaks in raw material quality (van der Vorst, 2000; Matopoulos et al., 2007), the fluctuation of the price of raw material (Matopoulos et al., 2007; Trkman and McCormack, 2009), the low level of supplier's education related to production and farm management, a centralized state that lacks the flexibility to rapidly adapt its regulations to market changes, poor financial systems, and contractual discipline and enforcement (van Veen, 2005), represent the main external factors that contribute to disturbances in the SME's supply chains.

P5. Riskiness of the product and the business environment characterise external vulnerability sources that likely increase the manufacturing SME's susceptibility to disturbances.

The impact of these vulnerability sources, however, is not high due to the combination of specificities of business environment characteristics and the use of impact reduction redesign strategies. For instance, in spite of government interventions in setting market prices and regulating competition in the dairy industry, as well as poor incentives and only partially developed a program for industry development, the company is reducing its vulnerability by exploiting knowledge of the local supply and demand market. For example, it uses close communication with selected local suppliers and a simplified form of tracking and tracing to provide insights into its regional supply market that enables it to predict both, raw material quality and availability. Thus, by building communication, relationship and trust with suppliers (Matopoulos et al., 2007; Dani and Deep, 2010), and by developing knowledge about the industry the company is increasing chances for timely reaction in the case of disturbances caused by external factors. 
P6. In the presence of both, product and business environment related risks, impact reduction redesign strategies are likely used to manage disturbances caused by external vulnerability sources.

\section{Conclusion, limitations and further research}

The supply chain risk management literature offers partial and conflicting findings in relation to the vulnerability of SME supply chains. It is highly likely that certain contextual factors play a significant role in successful disturbance management and the resulting vulnerability levels. The aim of the paper was to investigate an SME's susceptibility to disturbances, the vulnerability levels and the SME's ability to manage disturbances by considering relevant contextual factors.

The SME's supply chain is likely to be more susceptible to disturbances in the presence of contextual factors that carry certain levels of risk. Supply chains are product and company specific, (Reiner and Trcka, 2004), and details of their logistics and production processes depend on the business environment in which they operate (Trkman and McCormack, 2009). Thus, a 'risky' product and business environment can be indicative of an SME's susceptibility to disturbance and should raise questions about its ability to manage them.

We base these findings on an exploratory study of an SME's fresh food supply chain that operates in a developing market. These conclusions suggest that fresh food supply chains of SMEs in developing markets are prone to disturbances of their logistics and production processes due to the 'riskiness' of fresh food products, the 'riskiness' of developing market. Moreover, the SMEs are also characterised by risky features, i.e., limited organizational, financial and human resources that might influence their capability to manage disturbances. As a consequence, the SME manages disturbances by considering limitations imposed by these contextual factors and by choosing adequate redesign strategies. More specifically: 
- Riskiness of the products characterise internal, company related vulnerability sources that likely contribute to the SME's susceptibility to disturbances, while riskiness of the business environment might affect their capability to successfully manage disturbances. Manufacturing SMEs likely use preventive redesign strategies to manage disturbances that result from internal, company related vulnerability sources.

- Both, riskiness of the products and riskiness of the business environment characterise internal, supply chain related vulnerability sources that likely contribute to the SME's susceptibility to disturbances. However, there is strong indication that the riskiness of its product affects more the supply side of the SME's supply chain, while riskiness of the business environment affects more the demand side of the SME's supply chain. The SME's ability to use preventive strategies to manage disturbances is limited, and it is likely that the SME uses impact reduction redesign strategies to manage this kind of disturbances.

- Both, the riskiness of the products and the riskiness of the business environment characterise external vulnerability sources that likely contribute to the SME's susceptibility to disturbances. The SME likely manages disturbances by using impact reduction redesign strategies due to limited ability to use preventive strategies.

Thus, the findings show that though SMEs are susceptible to disturbances, this does not lead necessarily to the vulnerability of the SME and its supply chain if the right redesign strategies are implemented.

To conclude, the riskiness of the product and business environment characterise vulnerability sources and, thus, contribute to the SME's susceptibility to disturbances. Moreover, the findings indicate that these contextual factors might limit use of preventive redesign strategies. For example, disturbances that result from vulnerability sources characterised by riskiness of the business environment are managed by using impact reduction strategies. 
Therefore, it might be interesting to analyse whether this conclusion would change if this type of analysis is performed on a large company, which has more resources and power in the supply chain (Matopoulos et al., 2007). Disturbances that result from vulnerability sources characterised by the riskiness of the product are managed by using both preventive and impact reduction strategies. Similarly, it might be interesting to analyse whether use of preventive redesign strategies would increase if this analysis is performed on a large company, which can assess crucial resources in a supply chain and dominate in the supply chain (Cox, 1999).

Since the data is limited to one case study, it is difficult to estimate what contextual factors dominate in contribution to the SME's susceptibility to disturbances. However, supply related vulnerability sources tend to be characterised more by product related risks, while demand related vulnerability sources tend to be characterised more by business environment related risks.

The findings and conclusions are the result of a single exploratory case study and some statements might be industry specific. To generalize from these findings and build a theory of the vulnerability of SMEs' supply chains and robustness of their performance, it is necessary to test the stated propositions on other case studies. Moreover, an investigation of vulnerability levels is based on subjective estimation of frequency, impact and detectability of disturbances in an SME's supply chain with due consideration given to certain redesign strategies. The development of a simulation model could be helpful in investigating the effectiveness of certain redesign strategies in observed supply chains. 
Arend, R.J., Wisner, J.D., (2005). ‘Small business and supply chain management: is there a fit?’, Journal of Business Venturing, 20, pp. 403-436.

Arvis, J.F., Mustra, M.A., Ojala, L., Shepherd, B., Saslavsky, D., (2012), “Connecting to Compete 2012, Trade Logistics in the Global Economy, The Logistics Performance Index and Its Indicators”, The International Bank for Reconstruction and Development, The World Bank.

Asbjørnslett B.E., Rausand M. (1999) “Assess the vulnerability of your production system”, Production Planning \& Control, 10, 3, pp. 219 - 229;

Coe, N.M., Hess, M., (2005), ”The internationalization of retailing: implications for supply network restructuring in East Asia and Eastern Europe”, Journal of Economic Geography, 5, pp. 449-473.

Cox, A., (1999), "Power, value, and supply chain management”, Supply Chain Management: An International Journal, 4(4), pp. 167-175.

Dani, S., Deep, A., (2010), "Fragile food supply chains: reacting to risks”, International Journal of Logistics Research and Applications: A Leading Journal of Supply Chain Management, 13 (5), pp. 395-410.

Dong M. (2006) “Development of supply chain network robustness index”, Int. J. Services Operations and Informatics, Vol. 1, No. 1/2, pp. 54-66;

Donovan, J.A., Caswell, J.A., Salay, E., (2001), “The Effect of Stricter Foreign Regulations on Food Safety Levels in Developing Countries: A Study of Brazil”, Review of Agricultural Economics, 23(1), pp. 163-175.

Fynes, B., de Burca, S., Marshall, D., (2004), “Environmental uncertainty, supply chain relationship quality and performance”, Journal of Purchasing and Supply Management, 10, pp. 179-190.

Giunipero, L.C., Eltantawy, R.A., (2004), “Securing the upstream supply chain: a risk management approach”, International Journal of Physical Distribution and Logistics Management, 34 (9), 698713. 
Henson, S., Humphrey, J., (2010), “Understanding the Complexities of Private Standards in Global Agri-Food Chains as They Impact Developing Countries”, Journal of Development Studies, 46(9), pp. 1628-1646.

Henson, S., Reardon, T. (2005), "Private agri-food standards: Implications for food policy and the agrifood system”, Food Policy, 30, pp. 241-253.

Huiskonen, J., (2001), “Maintenance spare parts logistics: Special characteristics and strategic choices”, International Journal of Production Economics, 71(1-3), pp. 125-133.

Humphrey, J., (2007), “The supermarket revolution in developing countries: tidal wave or tough competitive struggle”, Journal of Economic Geography, 7, pp. 433-450.

Kleindorfer, P.R., Singhal, K., van Wassenhove, L.N. (2005), “Sustainable Operations Management”, Production and Operations Management, 14 (4), pp. 482-492.

Kleindorfer, P.R., Saad, G.H., (2005), “Managing Disruption Risks in Supply Chains”, Production and Operations Management, 14 (1), pp. 53-68.

Lambert, D.M., Cooper, M.C., (2000), “Issues in Supply Chain Management”, Industrial Marketing Management, 29, pp. 65-83.

Lorentz, H., Kittipanya-ngam, P., Srai, J.S., (2013), "Emerging market characteristics and supply network adjustments in internationalizing food supply chains”, International Journal of Production Economics, 145, pp. 220-232.

Matopoulos, A., Vlachopoulou, M., Manthou, V., Manos, B., (2007), “A conceptual framework for supply chain collaboration: empirical evidence from the agri-food industry”, Supply Chain Management: An International Journal, 12 (3), pp. 177-186.

Miles, M.B., Huberman, A.M., (1994), Qualitative Data Analysis, Sage Publications, Second edition, Thousand Oaks, California;

OECD (2012), “Competitiveness and Private Sector Development: Eastern Europe and South Caucasus 2011: Competitiveness Outlook”, OECD Publishing; 
Peck H. (2005) “The Drivers of Supply Chain Vulnerability: An Integrated Framework”, Int. J. of Physical Distribution and Logistics Management, Vol. 35, No. 4, pp 210-232;

Reiner, G., Trcka, M., (2004), “Customized supply chain design: Problems and alternatives for a production company in the food industry, A simulation based analysis”, International Journal of Production Economics, 89, pp. 217-229.

Ritchie, B., Brindley, C., (2000), “Disintermediation, disintegration and risk in the SME global supply chain”, Management Decision, 38 (8), pp. 575-583.

Roebuck, D.B., Sightler, K.W., Brush, C.C. (1995), “Organizational size, company type, and position effects on the perceived importance of oral and written communication skills”, Journal of Managerial Issues, 7(1), pp. 99-115;

Roth, A.V., Tsay, A.A., Pullman, M.E., Gray, J.V., (2008), "Unravelling the Food Supply Chain: Strategic Insights from China and the 2007 Recalls”, Journal of Supply Chain Management, Vol. 44, No 1, pp. 22-39.

Scipioni, A., Saccarola, G., Centazzo, A., Arena, F., (2002), "FMEA methodology design, implementation and integration with HACCP system in a food company”, Food Control, 13, pp. 495501

Simchi-Levi D., Kaminsky P., Simchi-Levi E. (2008), Designing and managing the supply chain, Concepts, Strategies, and Case Studies, III Edition, McGraw-Hill, Irwin;

Singh, R.K., Garg, S.K., Deshmukh, S.G., (2008), “Strategy development by SMEs for competitiveness: a review”, Benchmarking: An International Journal, 15 (5), pp. 525-547.

Slack, N., Brandon-Jones, A., Johnston, R., (2013), Operations management, VII edition, Pearson, London, UK.

Slone, R.E., Mentzer, J.T., Dittmann, J.P., (2007), “Are You the Weakest Link in Your Company’s Supply Chain?”, Harvard Business Review, pp. 1-10. 
Stonebraker, P. Goldhar, J., Nassos, G., (2009), “Weak links in the supply chain: measuring fragility and sustainability”, Journal of Manufacturing Technology Management, 20(2), pp. 161-177.

Tang C.S. (2006) "Robust strategies for mitigating supply chain disruptions”, International Journal of Logistics: Research and Applications, 9, 1, pp.33-45;

Taylor, D.H., (1994), "Problems of food supply chain logistics in Russia and the CIS”, International Journal of Physical Distribution and Logistics Management, 24(2), pp. 15-22.

Tibben-Lembke, R.S., Rogers, D.S., (2002), "Differences between forward and reverse logistics in a retail environment”, Supply Chain Management: An International Journal, 7 (5), pp. 271- 282;

Thun, J.-H., Drüke, M., Hoenig, D. (2011). 'Managing uncertainty - an empirical analysis of supply chain risk management in small and medium-sized enterprises', International Journal of Production Research, 49:18, pp. 5511-5525.

Trkman, P., McCormack, K., (2009), "Supply chain risk in turbulent environments - A conceptual model for managing supply chain network risk”, International Journal of Production Economics, 119, pp. 247-258.

Vaaland T.I., Heide, M., (2007), “Can the SME survive the supply chain challenges”, Supply Chain Management, An International Journal, 12/1, pp. 20-31.

Van der Vorst, J.G.A.J. (2000) “Effective food supply chains, Generating, modelling and evaluating supply chain scenarios”, doctoral dissertation, Wageningen University;

Van Veen, T.W.S. (2005), “International trade and food safety in developing countries”, Food Control, 16, pp. 491-496.

Vlajic, J.V., van der Vorst, J.G.A.J., Haijema, R., (2012), “Framework for designing robust supply chains”, International Journal of Production Economics, 137 (1), pp. 176-189;

Vlajic, J.V., (2012) "Robust food supply chains: An integrated framework for vulnerability assessment and disturbance management”, Doctoral thesis, Wageningen University, The Netherlands. 
Vlajic, J.V., van Lokven, S.W.M., Haijema, R., van der Vorst, J.G.A.J., (2013), “Using vulnerability performance indicators to attain food supply chain robustness”, Production Planning and Control, 24 (8/9), pp. 785-799.

Wagner, S.M., Bode, C., (2009), “Dominant Risks and Risk Management Practices in Supply Chains”, in (Eds.) Zsidisin, G.A., Ritchie, B., "Supply Chain Risk, A Handbook of Assessment, Management, and Performance”, pp. 271-290.

Wagner, S.M., Neshat, N., (2012), “A comparison of supply chain vulnerability indices for different categories of firms”, International Journal of Production Research, 50 (11), pp. 2877-2891.

Waters D. (2007) “Supply chain risk management, Vulnerability and Resilience in Logistic”, Kogan Page Limited;

Wieland, A., Wallenburg, C.M., (2012), “Dealing with supply chain risks, Linking risk management practices and strategies to performances”, International Journal of Physical Distribution and Logistics Management, 42(10), pp. 887-906

Yin, R.K., (2014), “Case Study Research, Design and Methods”, V edition, Sage, London.

Zsidisin, G.A., (2003), “Managerial perceptions of supply risk”, Journal of supply chain management, 39 (4), pp. 14-26. 